\title{
French version
}

Saroglou, V. (2006). Quête d'unité: Spécificité religieuse d'une fonction non nécessairement religieuse. Archives de Psychologie, 72, 161-181.

\section{English version}

Saroglou, V. (2007, June). Quest for unity: Religious specifics of a universal psychological function. Paper to be presented at the 2007 Metanexus Institute Conference, Philadelphia, PA, USA. (Text available soon at http://www.metanexus.net/conference2007 )

\section{Summary}

The needs for meaning, belonging, self-control, and self-esteem are some of the psychological needs traditionally considered as allowing us to understand the psychological functions of religion (Spilka et al., 2003). Indeed, these four needs correspond to the four classic components of religion: doctrine, community, rituals, and emotions. However, these psychological mechanisms are not specific to religion: they are universal, non-religious needs that can be satisfied outside a religious context.

Interestingly (not to say surprisingly), most philosophical, psychological, and evolutionary approaches do not recognize a specifically psychological function of religion: religion is supposed to be one among other ways used by human beings to satisfy universal needs not necessarily linked or pointing to religion.

Is it possible however to consider a psychological function that, although not necessarily exclusive to religion per se, is almost specific to it in terms of historical affinities? In other words, is it possible to consider a psychological need (or "quest", to avoid reductionism) for which one is hard put to find social realities outside religion that can satisfy this need/quest? Similarly, although there is a huge variety of religious forms and expressions across individuals, groups, religions, countries, and historical contexts - a variety corresponding to a diversity of psychological functions -, can we still conceive of a psychological function of religion that may make some claim to universality across this variety of contexts? Finally, is there a psychological function of religion the study of which would not only allow religious scholars to widen their understanding of religion through the use of psychological categories, but also (in the opposite direction) allow mainstream psychologists to widen their understanding of human beings by learning from the psychology of religious experience (see Hill, 1999)? Such a goal seems very important in an interdisciplinary approach to psychology, theology, and religious studies.

The present paper argues that quest for unity is a psychological quest that seems to fulfill this function. Although not exclusively religious in principle, this quest seems to have found in religion a social reality that almost entirely encompasses needs related to the quest for unity; it thus constitutes a psychological function having specific affinities with religion. This quest for unity may lay claim to some universality across the variety of contexts where religious expressions are manifest; and it may provide some insights for mainstream psychology, which has largely neglected the study of such a need.

In developing our argument, i.e. how the quest for unity seems related to religion in a specific and unique way, we distance ourselves from two approaches. A first one, purely descriptive, underlines the fact that religion simply puts an emphasis on the importance of avoiding conflict and promoting harmony between people. Our perspective, here, goes much further: we argue that human beings 
experience the feeling of an internal division in several, not to say most dimensions of their intrapsychic, interpersonal, and even cosmic life, and subsequently, that they aspire to a feeling of unity which would overcome the large number of internal divisions. Religion seems to be concerned with all of these divisions. The second perspective from which we distance ourselves is the psychoanalytic conception of the "oceanic feeling". Not that it is excluded that some reminiscence from the intra-uterine life can be a motivating basis of the need for unity and fusion, typical in love and mysticism according to many theorists. But we think, first, that the quest for unity is also prospective and doesn't only (or necessarily) have a regressive dimension; and second, that the quest for unity as theorized in the present paper has an explicative power that is more encompassing of many individual and social realities than the "oceanic feeling" that is traditionally supposed to explain mysticism (Parsons, 1999).

We inspect the large number of domains where an internal division can be observed in, and experienced by the human being, and we survey the several means religion seems to provide in each case to allow human beings to deal with, and eventually satisfy the quest for unity. These domains include a large number of realities in the intrapersonal, interpersonal, and cosmic dimensions of human life: gender differences, age and cohort differences, the distinctions (perceived as divisions) between the three temporalities (past, present, and future), life stages and periods, body and mind, emotions and cognition, moral judgments and moral action, private life and public life, nature and culture, myself and the others, humanity and the cosmos. Experiencing these internal divisions leads to a certain extent to the subjective experience of frustration. Our key argument is that, contrary to other social realities that may, to some extent, meet and satisfy needs for unity related to some of these internal divisions (see, e.g., the family, the nation, art, ideologies), the specificity of religion is that at least till now, historically speaking - it meets and possibly satisfies the entirety of the abovementioned internal divisions as a whole. In other words, its specificity with regard to the quest for unity is not this quest per se; it is the extent of the spectrum concerned.

Such a theoretical approach has some implications that help us to better understand specific religious realities. This quest for (broad) unity seems to be at the heart of realities specific to religion: conversion, mysticism, and asceticism. In addition, it helps us to better identify what is particular to religion when we apply to it the classic, universal psychological needs for meaning, self-esteem, and self-control: it is the connection of the latter three needs with the quest for unity that translates into religious terms the realization of the need for meaning, self-control, and self-esteem. In other words, the quest for unity plays the role of meta-function with regard to the other psychological functions implied in religion.

The quest for unity may also lay claim to being a universal function of religion across the variety of religious expressions. Two examples are taken into consideration for analysis. First, traditional expressions of religion may, at first glance, appear to suggest hierarchy rather than unity. Indeed, recent evolutionary approaches to religion emphasize the role religion plays in creating and maintaining hierarchies (Kirkpatrick, 2005). We argue that quest for unity is still present here as a psychological function and that there are at least two ways of attaining unity: one through equality (such an egalitarian pattern being more predominant in contemporary theologies), and the other through hierarchies that maintain and emphasize order, stability and unity (such an hierarchical pattern being more representative of traditional religious expressions). A simple inspection of how different religions have elaborated their representations of God is suggestive. Second, quest for unity also seems to be the key psychological function in modern spirituality, a contemporary reality that is theoretically and empirically distinct from traditional religiousness (e.g., Saroglou, 2003). The extent and the totality of intra-individual, inter-individual, and cosmic domains involved in modern spirituality parallel the ones of classic religion. Again, then, these domains include the following internal to 
human being divisions: gender differences, age and cohort differences, the distinctions (divisions) between the three temporalities (past, present, and future), life stages and periods, body and mind, emotions and cognition, moral judgments and moral action, private life and public life, nature and culture, myself and the others, humanity and the cosmos.

Finally, a specific danger may be inherent to religion as far as the quest for unity is concerned. The integration of the total number of domains under one and the same umbrella, i.e. religion, may accentuate tendencies towards totalitarianism. This has been an expression of fundamentalist religion as well. However, religions have also developed mechanisms that allow the realization of the quest for unity and at the same time avoid the temptation of totality. Empirical literature on religion and mental health suggests a similar pattern (Gartner, 1996): order, structure, unity, and control can be realized thanks to religion (in this way, religion compensates "under-control") and do not necessarily lead to dogmatic-like psychological realities ("over-control”).

Methodologically speaking, the present paper constitutes a theoretical argument that benefits greatly from an interdisciplinary approach to psychology and theology. It also makes use of two kinds of material: (a) a series of empirical studies in psychology of religion, allowing us to draw some constants regarding how religion and spirituality relate to personality, values, cognitive structures, social issues, and health; and (b) observation of theological ideas and religious practices and rituals that help us to exemplify how religion seems to deal with, and possibly satisfy a need for unity that covers all the domains where divisions internal to the human being can be observed.

Finally, the question arises why psychology has not extensively studied this quest for unity until now. From a developmental psychology perspective, there are of course some theories regarding integration and integrity as important developmental tasks, especially in adulthood. This is also the case in contemporary positive psychology, which emphasizes wisdom and optimal development as including integration. However, integration is only one way of looking for, and realizing unity. More importantly, there is still need for further investigation into what seems to be a universal human quest whose manifestations are explicit when one analyses religious forms and expressions, i.e. the universal quest for unity. Recent developments in research on magical thinking in children seem in favor of such a project (e.g., Woolley, 2000).

Gartner, J. (1996). Religious commitment, mental health, and prosocial behavior: A review of the empirical literature. In E. P. Shafranske (Ed.), Religion and the clinical practice of psychology (pp. 187-214). Washington, D.C.: American Psychological Association.

Hill, P. C. (1999). Giving religion away: What the study of religion offers psychology. International Journal for the Psychology of Religion, 9, 229-249.

Kirkpatrick, L. A. (2005). Attachment, evolution, and the psychology of religion. New York: Guilford Press.

Parsons, W. B. (1999). The enigma of the oceanic feeling: Revisioning the psychoanalytic theory of mysticism. New York: Oxford University Press.

Saroglou, V. (2003). Spiritualité moderne: Un regard de psychologie de la religion [Modern spirituality: A psychology of religion approach]. Revue Théologique de Louvain, 34, 473-504.

Spilka, B., Hood, R. W., Hunsberger, B., \& Gorsuch, R. (2003). The psychology of religion: An empirical approach (3d ed.). New York: Guilford Press.

Woolley, J. D. (2000). The development of beliefs about direct mental-physical causality in imagination, magic, and religion. In K. S. Rosengren, C. N. Johnson, \& P. L. Harris (Eds.), Imagining the impossible: Magical, scientific, and religious thinking in children (pp. 99-129). New York: Cambridge University Press. 